\title{
Correction to: Mosquito-borne heartworm Dirofilaria immitis in dogs from Australia
}

Chloe Nguyen ${ }^{1}$, Wei Ling Koh ${ }^{1}$, Andrea Casteriano ${ }^{1}$, Niek Beijerink², Christopher Godfrey², Graeme Brown ${ }^{3}$, David Emery ${ }^{1}$ and Jan Šlapeta ${ }^{1 *}$

\section{Correction to: Parasites \& Vectors (2016) 9:535}

\section{DOI: 10.1186/s13071-016-1821-x}

Since publication of the original version of this article [1], it has been flagged that unfortunately there is an error in dosage units in the Discussion section, in the sentence "For example a microfilaricide, either ivermectin (50-200 $\mathrm{mg} / \mathrm{kg}$ ) or milbemycin oxime $(500-1,000 \mathrm{mg} / \mathrm{kg}) "$.

Please be advised that the $\mathbf{m g}$ units in the sentence should instead be $\mu \mathrm{g}$; that is, "For example a microfilaricide, either ivermectin $(50-200 \mu \mathrm{g} / \mathrm{kg})$ or milbemycin oxime $(500-1,000 \mu \mathrm{g} / \mathrm{kg})$ ".

The authors apologize for any inconvenience caused.

\section{Author details}

${ }^{1}$ Faculty of Veterinary Science, The University of Sydney, McMaster Building B14, Sydney, NSW 2006, Australia. ${ }^{2}$ University Veterinary Teaching Hospital, Sydney (UVTHS), Faculty of Veterinary Science, The University of Sydney, Evelyn Williams Building B10, Sydney, NSW 2006, Australia. ${ }^{3}$ School of Life and Environmental Sciences, Faculty of Veterinary Science, The University of Sydney, McMaster Building B14, Sydney, NSW 2006, Australia.

Published online: 19 February 2019

\section{Reference}

1. Nguyen C, Koh WL, Casteriano A, Beijerink N, Godfrey C, Brown G, et al. Mosquito-borne heartworm Dirofilaria immitis in dogs from Australia.

Parasites \& Vectors. 2016;9:535.

\footnotetext{
* Correspondence: jan.slapeta@sydney.edu.au

${ }^{1}$ Faculty of Veterinary Science, The University of Sydney, McMaster Building B14, Sydney, NSW 2006, Australia

Full list of author information is available at the end of the article
} 